\title{
Quantification of calcium content in bone by using ToF-SIMS-a first approach
}

\author{
Anja Henss ${ }^{1}$, Marcus Rohnke ${ }^{1 *}$, Sven Knaack ${ }^{2}$, Matthias Kleine-Boymann ${ }^{1}$, Thomas Leichtweiss ${ }^{1}$, Peter Schmitz', \\ Thaqif El Khassawna ${ }^{3}$, Michael Gelinsky², Christian Heiss ${ }^{3,4}$ and Jürgen Janek ${ }^{1}$
}

\begin{abstract}
The determination of the spatially resolved calcium distribution and concentration in bone is essential for the assessment of bone quality. It enables the diagnosis and elucidation of bone diseases, the course of bone remodelling and the assessment of bone quality at interfaces to implants. With time-of-flight secondary ion mass spectrometry (ToF-SIMS) the calcium distribution in bone cross sections is mapped semi-quantitatively with a lateral resolution of up to $1 \mu \mathrm{m}$. As standards for the calibration of the ToF-SIMS data calcium hydroxyapatite collagen scaffolds with different compositions were synthesized. The standards were characterised by loss of ignition, $x$-ray diffractometry (XRD) and $x$-ray photoelectron spectroscopy (XPS). The secondary ion count rate for calcium and the calcium content of the standards show a linear dependence. The obtained calibration curve is used for the quantification of the calcium content in the bone of rats. The calcium concentration within an animal model for osteoporosis induction is monitored. Exemplarily the calcium content of the bones was quantified by XPS for validation of the results. Furthermore a calcium mass image is compared with an XPS image to demonstrate the better lateral resolution of ToF-SIMS which advances the locally resolved quantification of the calcium content.
\end{abstract}

Keywords: Calcium quantification bone; Time of flight secondary ion mass spectrometry; Osteoporosis; Bone imaging

\section{Background}

Quantification of the mineral content in osseous tissue is important for assessing bone quality-especially in case of bone diseases like such as osteoporosis. Dual energy $\mathrm{X}$-ray absorptiometry (DEXA) and quantitative computed tomography (Q-CT) are widely used for the clinical diagnosis of osteoporosis [1,2]. With DEXA X-ray absorption of the whole body is measured to determine the bone mineral density (BMD). However, DEXA does not sufficiently include bone thickness and bone volume when determining the BMD. Thus in clinical research micro-and nano-computed tomography $(\mu-\mathrm{CT}$ and $\mathrm{n}$ CT) with a spatial resolution of $10 \mu \mathrm{m}$ or $10 \mathrm{~nm}$, respectively, are often used for the complementary 3D analysis of bone architecture. Although DEXA and $\mathrm{Q}-\mathrm{CT}$ are essential, these $\mathrm{x}$-ray based methods are not chemically selective and do not allow the exclusive evaluation of the local $\mathrm{Ca}$ content.

\footnotetext{
* Correspondence: Marcus.Rohnke@phys.chemie.uni-giessen.de ${ }^{1}$ Institute of Physical Chemistry, Justus-Liebig-University of Giessen, Heinrich-Buff-Ring 58, 35392 Giessen, Germany

Full list of author information is available at the end of the article
}

Therefore, in bone research additional spectrometric and spectroscopic methods are applied to determine the elemental composition of bone samples. These include atom absorption spectroscopy [3] or inductively coupled plasma optical emission spectroscopy (ICP-OES) of ashed and dissolved bone samples, mostly applied to prove and quantify elements like $\mathrm{Pb}, \mathrm{Na}, \mathrm{K}, \mathrm{Al}, \mathrm{Mg}$ as well as $\mathrm{Ca}$ and $\mathrm{P}$ in bone $[4,5]$. Also laser ablation combined with inductively coupled plasma mass spectrometry (LA-ICP-MS) allows quantitative analysis and imaging in the lower $\mu \mathrm{m}$ regions [6]. Zoehrer et al. used $\mathrm{x}$-ray photoelectron spectroscopy (XPS) to evaluate the calcium and phosphorous content as well as the $\mathrm{Ca} / \mathrm{P}$ ratio to assess bone quality in case of fragility fractures of male patients [7]. In this study the well-established bone mineral density distribution (BMDD) was applied to characterise the degree and distribution of bone mineralisation. BMDD is calculated from backscattered electron images and is a validated method for the clinical use [8].

For the development of modified therapies and implants for patients with osteoporosis a profound knowledge about the local calcium distribution and content, 
especially in the most stressed and most fractured regions of the skeleton, is highly eligible. Time-of-flight secondary ion mass spectrometry (ToF-SIMS) as a surface sensitive technique is chemically specific and offers high spatial resolution-its applicability for the investigation of biological samples and biomaterials interfaces has already been demonstrated in several cases so far $[9,10]$. In our previous studies ToF-SIMS was successfully applied for the analysis of osteogenic differentiated hMSCs, for tracking pharmaceuticals in a biomaterial from in vitro to in vivo experiments, as well as for the investigation and imaging of osteoporotic bone in an animal model [11-13]. ToF-SIMS provided detailed chemical information of bone with high sensitivity and a lateral resolution of up to $300 \mathrm{~nm}$. Mass images revealed the distribution of the organic compounds as well as the localisation of mineralised parts of the bone. Assuming the secondary ion count of calcium to be proportional to its surface concentration, a semi-quantitative comparison of healthy and osteoporotic bone confirmed the reduction of the calcium content in diseased tissue, as proven additionally by DEXA measurements [11].

In the present paper a first step toward the quantitative evaluation of the $\mathrm{Ca}$ content of bone is reported, thereby expanding the use of ToF-SIMS for the analysis of osseous tissue. Generally, quantification of concentrations using ToF-SIMS is challenging, as the ionisation process and hence the ion yields strongly depend on the chemical environment of the elements and molecules at the surface [14]. Therefore appropriate standards with an almost identical chemical composition as the analysed material are required, and the relative fragment mass intensity of the analyte of interest should follow a linear relationship with its concentration in the standard. For quantification in biological systems internal standards are often used to derive a calibration curve, or sensitivity factors are estimated from a model matrix [15]. For the quantification of $\mathrm{Ca}$ in healthy trabecular bone the standards should consist of collagen with $60-70 \mathrm{wt} \%$ of mineralised hydroxyapatite (HAP) or correspondingly less for osteoporotic bone. Once the quantification with ToF-SIMS is reliable, distinct additional benefit is gained. ToF-SIMS has a higher lateral resolution in contrast to XPS, and in comparison with BMDD from SEM images, ToF-SIMS allows to distinguish unequivocally between different elements (e.g. differentiation of $\mathrm{Sr}$ and $\mathrm{Ca}$ ).

\section{Methods}

\section{Preparation of the mineralised collagen standards}

Scaffolds from mineralised collagen I [16] were prepared by synchronous mineralisation of a collagen type I solution according to a method developed by Bradt et al. [15]. The procedure was published in detail elsewhere [17].
To describe the procedure briefly, acid-soluble collagen type I isolated from calf skin (Collaplex 1.0, GfN, Wald-Michelbach, Germany) was dissolved in $10 \mathrm{mM}$ $\mathrm{HCl}$ and mixed with a $\mathrm{CaCl}_{2}$ solution. The $\mathrm{pH}$ was adjusted to 7 by addition of TRIS and phosphate buffer and the mixture then warmed to $37^{\circ} \mathrm{C}$ for $12 \mathrm{~h}$. Under these conditions collagen fibril reassembly and formation of nano-crystalline HAP occurs simultaneously. The product-homogeneously mineralised collagen fibrils-was collected by centrifugation. By variation of the collagen to calcium and phosphate ratio in the precursor mixture the collagen to mineral ratio in the final product could be adjusted.

To prepare the standards, thoroughly resuspended mineralised collagen was condensed by vacuum filtration using a porous G4 glass filter frit (Schott, Germany) and then cross-linked with an aqueous solution of $1 \% \mathrm{~N}$ (3-dimethylaminopropyl)-N'-ethyl carbodiimide hydrochloride (EDC; Merck, Germany) for $1 \mathrm{~h}$. Finally, the scaffolds were rinsed in distilled water, in $1 \%$ glycine solution, once again in water, and freeze dried.

\section{XRD of standards}

XRD analysis was carried out in scanning mode with $\mathrm{Cu}$ $\mathrm{K}_{\alpha}$ and $\mathrm{Cu} \mathrm{K}_{\beta}$ radiation on a Panalytical X'Pert PRO instrument. The $\mathrm{Cu}$ anode was operated at $40 \mathrm{kV}$ and $40 \mathrm{~mA}$. Samples were rotated during measurement. For the data analysis only $\mathrm{Cu} \mathrm{K}_{\alpha}$ lines were used, and the XRD pattern was compared with entries in the ICSD database.

\section{X-ray photoelectron spectroscopy (XPS)}

XPS measurements were carried out with a PHI 5000 Versaprobe Scanning ESCA Microprobe (Physical Electronics) using a monochromatic $\mathrm{Al} \mathrm{K}_{\alpha} \mathrm{X}$-ray source $(\mathrm{h} v=1486.6 \mathrm{eV})$.

\section{Analysis of the standards}

Quantitative analysis of the standard samples was performed by recording detailed spectra for the elements of interest. An x-ray spot size of $100 \mu \mathrm{m}$ diameter was used and the analyser pass energy was set to $23.5 \mathrm{eV}$. After subtraction of a Shirley-type background function, elemental concentrations were calculated from the peak areas by applying the appropriate sensitivity factors (provided by the instrument manufacturer). Assuming that all $\mathrm{Ca}$ originates from HAP (formula $\mathrm{Ca}_{5}\left(\mathrm{PO}_{4}\right)_{3} \mathrm{OH}$ ), the HAP content is evaluated on the basis of the $\mathrm{Ca}$ content in at $\%$ and $\mathrm{wt} \%$.

\section{Analysis of bone cross sections}

Elemental mapping was carried out for $\mathrm{C}$ 1s (for energy calibration) $\mathrm{O} 1 \mathrm{~s}, \mathrm{~N} 1 \mathrm{~s}, \mathrm{P} 2 \mathrm{p}$ and $\mathrm{Ca} 2 \mathrm{p}$ lines with a pass energy of $93.9 \mathrm{eV}$ and a spot size of the focussed $\mathrm{x}$-ray 
beam of $15 \mu \mathrm{m}$ in diameter at $2.5 \mathrm{~W}$. The energy interval of each signal was partitioned into sixteen intervals, each of them was than assigned to one specific channel of the multi-channel detector to reduce measurement time. The analysed area was $500 \times 500 \mu \mathrm{m}^{2}$ divided in $128 \times 128$ pixels.

In addition to the XPS imaging detailed point spectra were recorded on the same areas that were investigated by mapping. We therefore selected three spots of interest on every sample, which were a) on the trabecular structure, b) on the edge of the trabecular and c) on an area far away from the trabecular. Here, we recorded detail spectra for $\mathrm{C} 1 \mathrm{~s}$ (for energy calibration) $\mathrm{O} 1 \mathrm{~s}, \mathrm{~N} 1 \mathrm{~s}$, $\mathrm{P} 2 \mathrm{p}$ and $\mathrm{Ca} 2 \mathrm{p}$ with a spot size of $15 \mu \mathrm{m}$ in diameter at $2.5 \mathrm{~W}$. The pass energy was set to $23.5 \mathrm{eV}$. Elemental concentrations were calculated as described above.

For evaluation of the HAP content of the bone samples we used a calibration factor $F(F=1.15)$, which was determined by the ratio of the measured and the nominal $\mathrm{Ca}$ content obtained by the analysis of pure hydroxyapatite as reference material. Further details of the XPS analysis of calcium phosphate phases and systematic errors of calculated $\mathrm{Ca}$ and $\mathrm{P}$ concentrations are described elsewhere (Kleine-Boymann M, Rohnke M, Sann J, Henss A, Janek J, Differentiation of biologically relevant calcium phosphate phases by surface-sensitive techniques, submitted to Appl Surf Sci).

\section{Time-of-flight secondary ion mass spectrometry (ToF-SIMS)}

ToF-SIMS data of the standards and bone samples were collected in the positive ion mode on a TOF.SIMS 5-100 machine (IonTOF Company, Münster, Germany) equipped with a bismuth cluster primary ion source (25 keV) and $\mathrm{Cs}, \mathrm{O}_{2}$ and $\mathrm{C}_{60}$ sputter guns. Spectra were acquired using $25 \mathrm{keV} \mathrm{Bi}{ }_{3}^{+}$primary ions $(\sim 0.3 \mathrm{pA}$ pulsed current) with a primary ion dose of $\sim 7 \cdot 10^{12} \mathrm{~cm}^{-2}$, $100 \mu \mathrm{s}$ cycle time and operated in the high-currentbunched mode (hc-bu). Ions were registered within the mass range from $m / z=1$ to $800 \mathrm{u}$ with high mass resolution of about 6000 FWHM (full width half maximum) at $m / z=29.00 \mathrm{u}$ (e.g. the fragment $\mathrm{CHO}$ ) and a spatial resolution of $<10 \mu \mathrm{m}$. Six to seven measurements were taken of each prepared standard material on different areas of $49.5 \times 49.5 \mu^{2}$ with $128 \times 128$ pixels and 50 scans. The analysis of the Ca concentration of trabecular bone was carried out by measurement of 3-5 areas of a size of $49.5 \times 49.5 \mu \mathrm{m}^{2}$ on the trabeculae of each sample. After normalization to the applied primary ion current, the mean values for the Ca signal intensity of the various groups were calculated. Due to the linear dependence of the normalized Ca-signal intensity from the HAP content of the scaffolds, a linear fit was possible and a linear equation (1) was obtained. The equation reveals the dependence of the signal intensity ( $I$ (counts)) from the HAP content $(x(\mathrm{wt} \%))$ by the factor $(9265 \pm 581)$ $\left(\frac{\text { counts }}{\text { wt\% }}\right)$, slope of the line respectively. So for the subsequent calculation of the HAP content equation (1) was used.

$$
I(\text { counts })=(9265 \pm 581)\left(\frac{\text { counts }}{\mathrm{wt} \%}\right) \cdot x(\mathrm{wt} \%)
$$

The mass image was taken in the low current bunched mode (lc-bu), where good mass resolution is combined with an optimized lateral resolution of about $1 \mu \mathrm{m}$. The applied primary ion current was $0.13 \mathrm{pA}$.

\section{Sample preparation of bone cross sections}

For the application and testing of the calibration curve bone samples from a long-term small animal model for osteoporosis induction were used. Osteoporosis was induced in female Sprague-Dawley rats by ovariectomy (OVX) combined with a special multi-deficiency diet. The animal study was performed in full compliance to the German animal protection laws and was approved by the ethical commission of the local governmental institution ("Regierungspräsidium" Giessen, Germany, permit number: 89/2009 \& 20/10-No. A31/2009). The protocol and procedures employed in the animal experiment were reported previously in detail [18].

Vertebrae samples of three different groups were analysed: A sham group with 13 animals (time of euthanasia in months, number of animals; 3,$7 ; 12,6)$, OVX + diet group with 14 animals $(3,7 ; 12,7)$ and the reference group with 8 animals at the beginning of the experiment $(0,8)$. After euthanasia at distinct times $(0,3$, and 12$)$ the vertebrae samples were embedded in poly methyl methacrylate (Technovit 9100; Heraeus Kulzer, Hanau, Germany) and afterwards cut and ground into slides of $20 \mu \mathrm{m}-50 \mu \mathrm{m}$ thickness.

\section{Statistical analysis}

The data were checked for statistical significance by the one-way ANOVA test accompanied by Games-Howell pair wise multiple comparisons to determine the variation of the $\mathrm{Ca}$ content in each group, among groups at particular times and throughout the whole experiment. The asterisks indicate the significance level $(* p<0.05$, $* * p<0.01, * * * 0.001)$. The results were expressed as mean and standard error. The statistical analysis was done using the software IBM SPSS Statistics 20.

\section{Results and discussion}

The mineralised collagen scaffolds have been synthesized in a synchronous biomineralisation process leading to a nano-composite material of collagen fibrils and nanocrystalline HAP. The formation of an apatite-like phase 


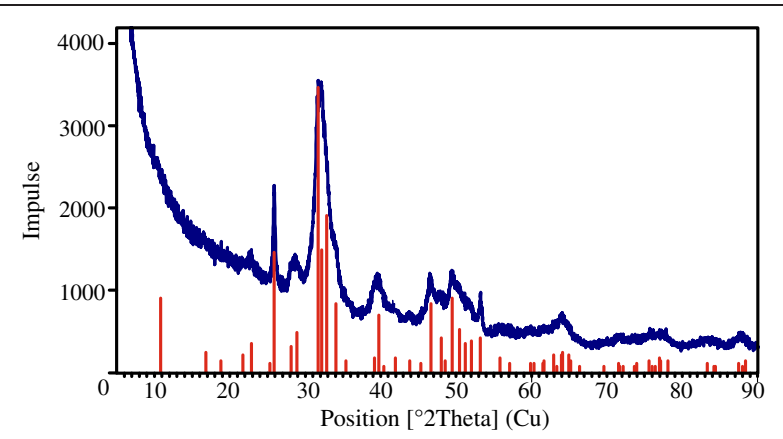

Figure 1 X-ray diffraction pattern (XRD) of nano-crystalline hydroxyapatite (HAP) mineralised on a collagen scaffold (CuKa radiation). The pattern from ICSD database is shown in red colour.

has been proven by $\mathrm{x}$-ray diffraction (XRD), shown in Figure 1. The scaffolds have also been characterized in detail by infrared spectroscopy (IR) [19] and SEM [17] and its micro-porous 3-D modification by SEM and TEM [20]. Several samples with different HAP content (weight per cent) were produced by varying the ratio of collagen and calcium phosphate precursor. To reveal the exact composition, the samples were ashed completely and the $\mathrm{Ca}$ content was calculated from the residue. Previous studies showed that the scaffolds still contain a small part of water but apart from that they are exclusively composed of collagen and minerals. So the HAP content was found to be 54-81 wt\% with 14-41 wt\% collagen, which is an appropriate composition for the use of these materials as standard materials for the quantification of healthy and osteoporotic bone via ToF-SIMS. The results of the bulk analysis are given in Table 1.

As ToF-SIMS is a purely surface sensitive technique in the static mode, only the uppermost molecular layers are analysed. Inhomogeneous samples or surface segregation can result in different bulk and surface compositions. Thus, bulk information (like HAP content) as determined by ignition loss of the standard materials is not feasible in any case for the quantitative evaluation of the Ca content with ToF-SIMS. Therefore XPS was applied as a surface sensitive and quantitative method to determine the surface content of $\mathrm{Ca}$. Based on this, the HAP content was calculated assuming the sum formula $\mathrm{Ca}_{5}\left(\mathrm{PO}_{4}\right)_{3} \mathrm{OH}$. A typical survey spectrum is shown in Figure 2a. It indicates the main components carbon, oxygen, calcium and phosphorous, as expected. The results of the quantification of the HAP content at the surface are given in Table 1 . They show a significant systematic deviation to lower values from the bulk values obtained by ashing. McLeod et al. also found a significant difference between the $\mathrm{Ca} / \mathrm{P}$ ratio of bulk and surface for deposited layers of HAP [21]. They also detected a decreased $\mathrm{Ca} / \mathrm{P}$ ratio on the surface compared to the bulk material. This might be due to a Ca deficit on HAP surfaces like observed by us with our standards and which has been reported in other studies as well $[22,23]$. Figure $2 \mathrm{~b}$ shows the linear correlation between the measured surface concentration of $\mathrm{Ca}$ and the bulk content of HAP (wt\%) given by ignition loss of the samples.

The subsequent ToF-SIMS analysis of the standards showed mass signals (ion, $m / z$ value;) of HAP and collagen like $\mathrm{Ca}^{+}, 39.96 ; \mathrm{Ca}_{2} \mathrm{PO}_{4}^{+}, 174.87 ; \mathrm{Ca}_{3} \mathrm{PO}_{5}^{+}, 230.83$; $\mathrm{Ca}_{5} \mathrm{P}_{3} \mathrm{O}_{12}^{+}, 484.12$ and $\mathrm{C}_{4} \mathrm{H}_{8} \mathrm{~N}^{+}, 70.07$ for example. A typical positive mass spectrum with some more labelled HAP fragments is given in Figure $3 \mathrm{~b}$. The comparison with mass spectra of mineralised tissue reveals almost identical mass spectra with characteristic peaks and fragmentation patterns of HAP and collagen, which are well known from our study of bony tissue amongst others $[11,24]$. The plot of the obtained signal intensities of $\mathrm{Ca}$ versus the surface concentration obtained from XPS measurements results in a linear relationship, see Figure 3c. This linear correlation is an important prerequisite for the target quantification. It demonstrates that the matrix effect is negligible within the concentration ranges of about 9-76 wt\% HAP and that quantification is well possible. Nevertheless, the error bars indicate an appreciable deviation of the $\mathrm{Ca}$ signal intensities measured with ToF-SIMS. The surfaces of the standards were surely not ideally planar which influenced the signal intensity and is responsible for part of the error. However, despite of the effect of the sample roughness the linear relationship between $\mathrm{Ca}$ signal intensity and $\mathrm{Ca}$ content clearly indicates that the samples are suitable standards within the error tolerances for a first approach of $\mathrm{Ca}$ quantification of bone.

After analysis of the standards several cross sections of rat vertebrae were analysed using the same measurement conditions. The osteoporotic induction applied over several months allows a tracking of the degradation of the bone which comes along with a reduction of the bone mineral content and density [18]. In a previous study these results were confirmed by a semi quantitative analysis of the Ca content [11]. Applying the linear equation (1) of diagram $3 c$, the semi-quantitative evaluation is

Table 1 HAP content of the mineralised collagen scaffolds

\begin{tabular}{|c|c|c|c|c|c|c|c|c|c|}
\hline Sample & S 1 & S 2 & S 3 & S 4 & S 5 & S6 & S7 & S8 & S9 \\
\hline Bulk (Ignition) HAP (wt\%) & 67 & 54.2 & 78.4 & 81.2 & 59.4 & 69.7 & 76.1 & 62.1 & 72.9 \\
\hline Surface (XPS) HAP (wt\%) & 40.8 & 8.8 & 69.1 & 74.7 & 21.9 & 49.9 & 69.3 & 26.6 & 50.1 \\
\hline
\end{tabular}

HAP content evaluated by ignition loss and by XPS measurements (surface content): The mean error for the quantification by XPS accounts to $\pm 10 \%$. 

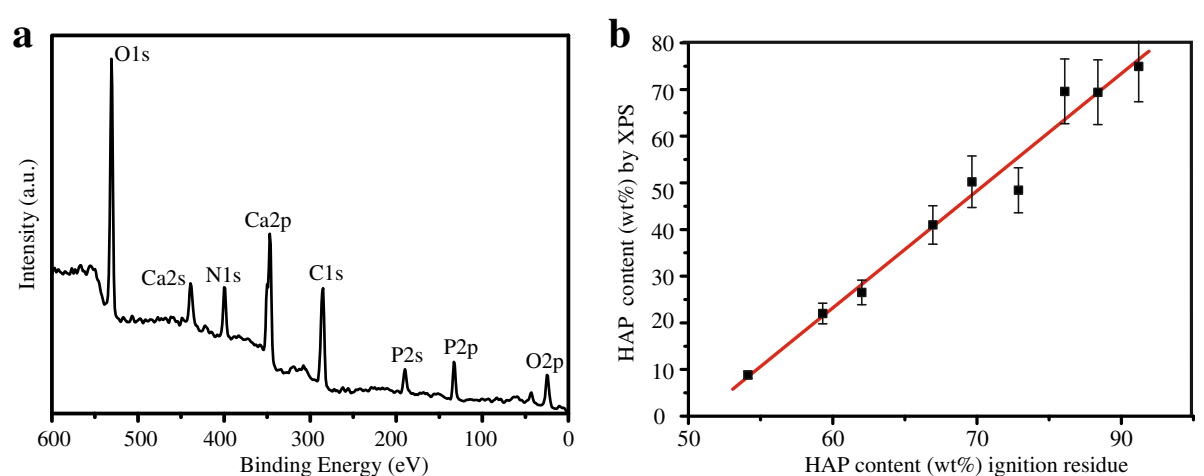

Figure 2 XPS survey spectrum and cross correlation for surface and bulk concentrations. a) Exemplary XPS survey spectrum of a mineralised scaffold showing the five compositional elements $\mathrm{Ca}, \mathrm{P}, \mathrm{N}, \mathrm{C}, \mathrm{O}$ and $\mathbf{b}$ ) the linear relationship of the HAP content evaluated by XPS versus the HAP content determined by ignition residue of the mineralised collagen standards.

improved to become a truly quantitative analysis of the HAP content as shown in Figure 3d. The results are given in Table 2.

The obtained mean values for the HAP content of the analysed trabeculae agree well with the realistic range of HAP concentration for healthy bone. It is known that healthy bone consists of about 70\% HAP [25], which is in fairly good agreement with the result of $62 \%$ HAP at the beginning of the animal experiment (reference group). Due to the maturing of the animals an increase of the HAP content is expected and is documented by
76\% HAP after 3 months for the sham operated, healthy animals. Beside this a remarkable and statistical significant reduction of about $50 \%$ of the HAP content for the osteoporotic animals (OVX + diet group) can be found. However, the extreme reduction revealed by ToF-SIMS measurements is plausible and a qualitative comparison with BMD evaluated by DEXA measurements shows the same tendencies although not to this extent [18]. Due to the experimental conditions, like the $\mathrm{Ca}$ and Vitamin $\mathrm{D}$ deficient diet, wide regions of the trabeculae are not mineralised anymore, which indicates rather osteomalacia
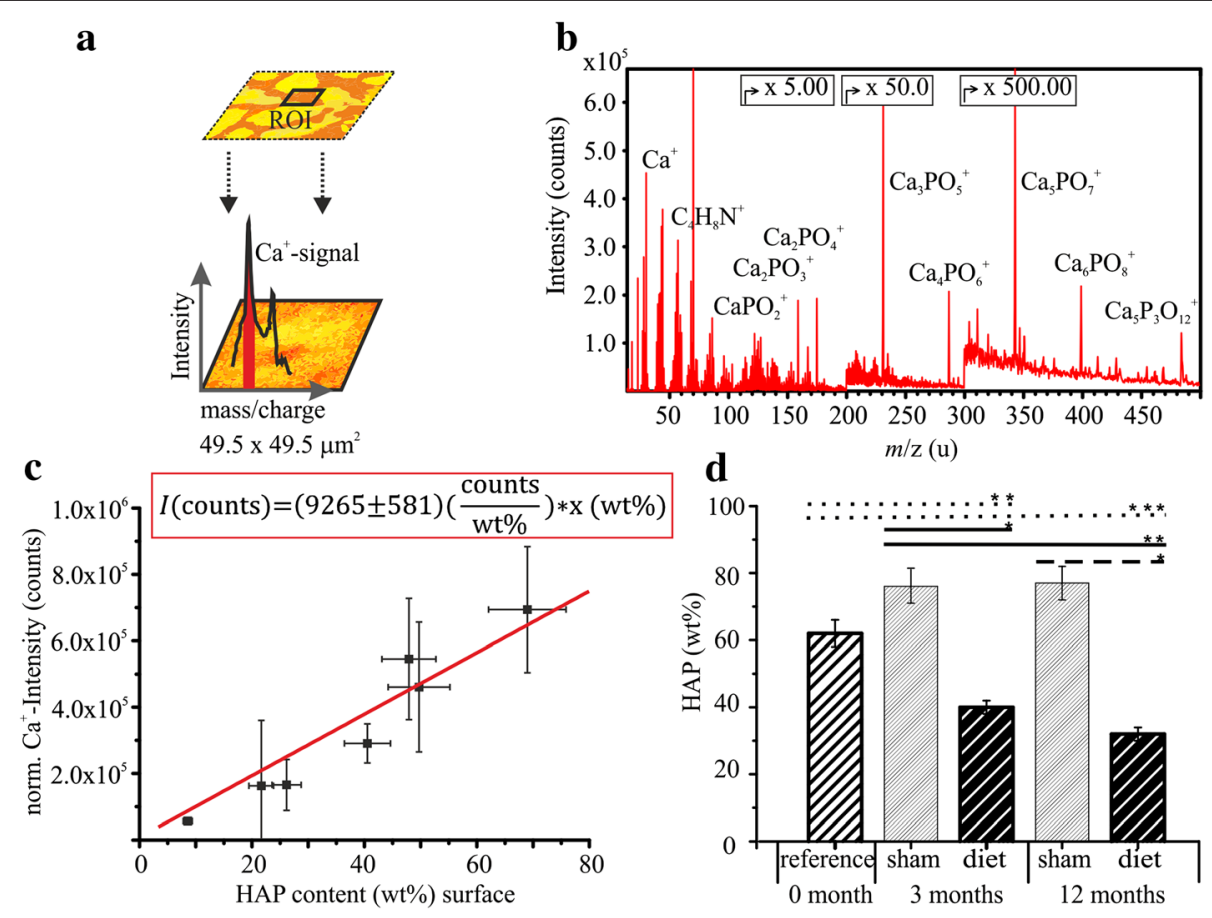

Figure 3 ToF-SIMS data from standards and rat bone. a) Schematic graph of the ToF-SIMS analysis of trabecular bone. b) Positive ion mass spectrum of a mineralised scaffold showing the expected HAP fragments up to high masses [24]. c) Linear dependence of the normalized Ca-signal intensity from the HAP content of the scaffolds. Linear fit and the linear equation are shown. $\mathbf{d}$ ) Summary of the Ca quantification results for different groups and different times after osteoporosis induction in rats. 
Table 2 HAP content of rat trabeculae of various groups at different times evaluated by ToF-SIMS

\begin{tabular}{cccccc}
\hline $\begin{array}{c}\text { Time } \\
\text { (months) }\end{array}$ & Group & $\begin{array}{c}\text { Norm. } \\
\text { Ca-Intensity } \\
\text { (counts) }\end{array}$ & $\begin{array}{c}\Delta \text { Intensity } \\
\text { (counts) }\end{array}$ & $\begin{array}{c}\text { Content } \\
\text { HAP } \\
\text { (wt\%) }\end{array}$ & $\begin{array}{c}\Delta \text { HAP } \\
\text { (wt\%) }\end{array}$ \\
\hline 0 & reference & $5.8 \cdot 10^{5}$ & $7.6 \cdot 10^{4}$ & 62 & 4 \\
3 & sham & $7.0 \cdot 10^{5}$ & $1.4 \cdot 10^{5}$ & 76 & 5 \\
3 & diet & $3.7 \cdot 10^{5}$ & $6.7 \cdot 10^{4}$ & 40 & 2 \\
12 & sham & $7.1 \cdot 10^{5}$ & $1.8 \cdot 10^{4}$ & 77 & 5 \\
12 & diet & $3.0 \cdot 10^{5}$ & $8.0 \cdot 10^{4}$ & 32 & 2 \\
\hline
\end{tabular}

Mean values and deviation from the mean value of the normalized Ca-signal intensities determined for different groups and different times after

osteoporosis induction and the corresponding absolute HAP content (wt\%) evaluated by equation (1). $\triangle \mathrm{HAP}$ is given by the standard error of the slope of Figure 3c.

than osteoporosis. The non-mineralised collagen matrix with small remains of $\mathrm{Ca}$ in the centre of the trabecular has been described in more detail in our previous study [11]. After histological and serological investigations El Khassawna et al. also conclude the development of osteomalacia in this rat model [26]. In consequence the $\mathrm{Ca}$ quantification might become more complicated due to measurement of non-mineralised regions which might result in too low Ca values for the OVX and diet group.

To further validate the ToF-SIMS measurements and the quantification by the calibration curve, several cross sections were analysed by XPS allowing quantification and elemental mapping. The elemental mapping of the $\mathrm{Ca} 2 \mathrm{p}$ and $\mathrm{N}$ 1s signal is shown in Figure 4a1 and $4 \mathrm{a} 2$. The Ca $2 p$ signal allows the identification of the mineralised
Table 3 HAP content of osteoporotic and nonosteoporotic trabeculae evaluated by XPS and ToF-SIMS

\begin{tabular}{cccccc}
\hline & \multicolumn{2}{c}{$\mathbf{1 2}$ months sham } & & \multicolumn{1}{c}{$\mathbf{1 2}$ months diet } \\
\cline { 2 - 3 } XPS analysis & at\% & wt\% & & at\% & wt\% \\
\hline C & 43.1 & 30.0 & & 56.2 & 40.9 \\
N & 37.7 & 35.0 & & 26.3 & 25.5 \\
Ca & 4.1 & 3.3 & & 11.1 & 9.4 \\
P & 8.6 & 20.0 & & 3.8 & 9.2 \\
Calculated HAP (wt\%) & 6.5 & 11.7 & & 2.6 & 4.9 \\
Corrected HAP (wt\%) XPS & & 51.3 & & 23.2 \\
HAP (wt\%) ToF-SIMS & & $\mathbf{5 9 . 2}$ & & $\mathbf{2 6 . 8}$ \\
By calibration curve & & $\mathbf{5 1 . 6}$ & & $\mathbf{2 4 . 0}$
\end{tabular}

HAP content of osteoporotic (12 months diet) and non-osteoporotic (12 months sham) trabeculae of the rat. The evaluation of the HAP content by XPS and ToF-SIMS measurement is described in the Methods section. The error for the quantification by XPS amounts to $10 \%$ while for ToF-SIMS the error accounts to $6 \%$, given by the standard error of the slope of Figure $3 \mathrm{c}$ (equation (1)).

structure of the trabeculae while the $\mathrm{N}$ 1s signal corresponds to the collagen matrix of the vertebrae. To quantify the mineral content of the trabeculae detail spectra were recorded from the mineralised regions. The results are given in Table 3 and are in good agreement with the $\mathrm{Ca}$ content evaluated by the ToF-SIMS measurement. Due to the spatial resolution of only $15 \mu \mathrm{m}$ a spatially selective analysis of trabeculae with only $50 \mu \mathrm{m}$ in diameter is not very precise as the unintended measurement of bone marrow or embedding material will falsify a1

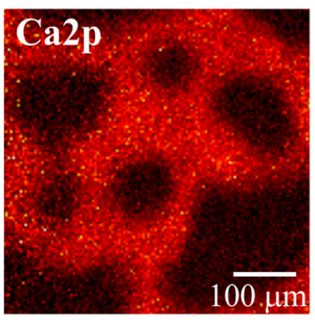

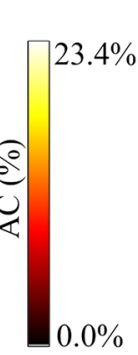

b1

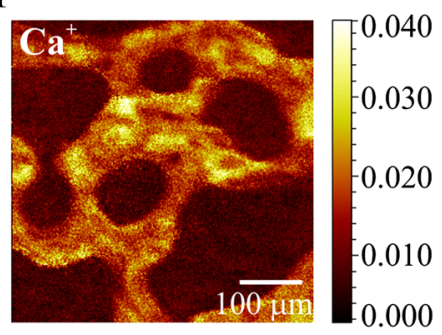

$\mathbf{a} 2$

b2
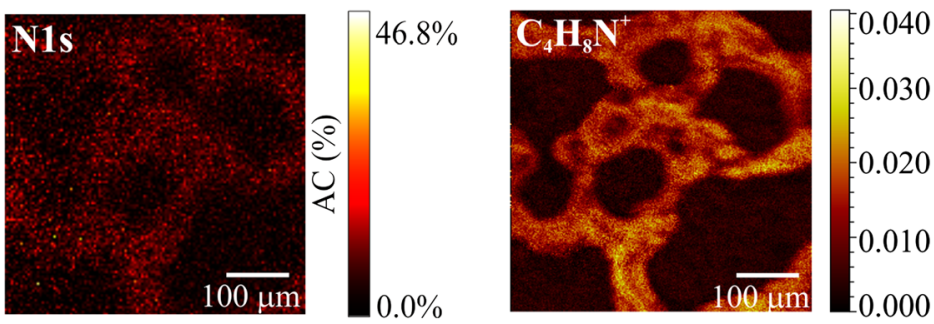

Figure 4 XPS and ToF-SIMS Ca and collagen distributions in bone cross sections. XPS (a1, a2) and ToF-SIMS (b1, b2) images of the same area of a non-osteoporotic vertebra of a 12 months sham rat. Mapping of the Ca 2p intensity (a1) represents the mineralised part while mapping of the $\mathrm{N} 1 \mathrm{~s}$ intensity (a2) represents the collagen structure of the trabeculae. The corresponding ToF-SIMS images of the $\mathrm{Ca}^{+}-$and $\mathrm{C}_{4} \mathrm{H}_{8} \mathrm{~N}^{+}$- signals also represent the mineralised part (b1) and the collagen matrix (b2) but with a much better lateral resolution. 
the result. ToF-SIMS offers a much better lateral resolution and indeed enables analysis with sufficient spatial resolution. Figure $4 \mathrm{~b} 1$ and $4 \mathrm{~b} 2$ show ToF-SIMS images recorded with a lateral resolution of $1 \mu \mathrm{m}$ for comparison with the XPS-map of the same region (Figure 4a).

Finally, we like to note that further improvements will be possible. Trabecular bone does not consist of pure HAP, rather it is known that HAP is only the final phase of matured bone. During the process of bone formation different $\mathrm{Ca}$ phosphate phases like amorphous calcium phosphate (ACP) or octa calcium phosphate (OCP) are formed [27]. At the end of this process usually a Ca deficient HAP phase is found. Moreover, the matured HAP is not a pure hydroxyapatite mineral. Also other anions like fluoride or carbonate are part of the crystal structure [28]. Therefore our current approach to equate the $\mathrm{Ca}$ content with the HAP content of the bone samples according to the formula $\mathrm{Ca}_{5}\left(\mathrm{PO}_{4}\right)_{3} \mathrm{OH}$ should only be considered as a first successful step. It is a quite challenging task to synthesise and test standards, which are comparable to natural bone in composition, lattice structure of the crystalline component, density and surface roughness. However, optimized standards will help to further improve the validity of ToF-SIMS data.

\section{Conclusions}

Calcium quantification by ToF-SIMS is possible, however, the quality of the results is strongly affected by the surface properties of the standards. Although the standards consisted of collagen and HAP comparable to normal bone-which makes the matrix-effect differences of the standards and bone negligible-the surface roughness is not really suitable for the ToF-SIMS measurements. Despite the influence of the surface morphology, the present results are encouraging. A linear relation is obtained between the Ca secondary ion counts rate and the Ca concentration of the prepared standards. The application of the calibration data to natural rat bone samples leads to plausible results, which were cross-checked by XPS measurements. As the ToF-SIMS analysis offers information on both organic and inorganic components of osseous tissue with high spatial resolution, the quantification of the Ca content based on the ToF-SIMS measurements might become a useful and complementary method to assess bone quality and damage. Future work on improved standards will allow a more precise quantification with smaller error. The mapping of various $\mathrm{Ca}$ concentrations and of different calcium phosphate phases to track the mineralisation process will be further useful applications of ToF-SIMS.

\section{Competing interests}

The authors declare that they have no competing interests.

\section{Authors' contributions}

AH carried out the ToF-SIMS measurements, evaluated and interpreted the data and drafted the manuscript. MR assisted in the design of the experiments, data evaluation and revised the manuscript. SK synthesized and ashed the standard materials. MKB and TL carried out the XPS measurements and XPS data evaluation. PS recorded the shown ToF-SIMS image. $\mathrm{CH}$ and TEK designed and carried out the animal experiments including sample preparation. MG has been involved in drafting the manuscript. JJ adjusted and proofread the manuscript. All authors read and approved the final manuscript.

\section{Acknowledgement}

We gratefully acknowledge funding and support by the Deutsche Forschungsgemeinschaft (DFG, German Research Foundation) within the collaborative research centre-SFB/TRR 79 "Materials for tissue regeneration within systemically altered bone", projects M5, M4 and T1.

\section{Author details}

${ }^{1}$ Institute of Physical Chemistry, Justus-Liebig-University of Giessen, Heinrich-Buff-Ring 58, 35392 Giessen, Germany. ${ }^{2}$ Centre for Translational Bone, Joint and Soft Tissue Research, Technische Universität Dresden, Fetscherstrasse 74, 01307 Dresden, Germany. 'Laboratory of Experimental Trauma Surgery, University of Giessen, Kerkrader Strasse 9, 35394 Giessen, Germany. ${ }^{4}$ Department of Trauma Surgery, University Hospital of Giessen-Marburg, Rudolf-Buchheim-Strasse 7, 35385 Giessen, Germany.

Received: 2 October 2013 Accepted: 4 November 2013

Published: 14 November 2013

\section{References}

1. Blake GM, Fogelman I (2007) The role of DXA bone density scans in the diagnosis and treatment of osteoporosis. Postgrad Med J 83(982):509-517

2. Engelke $\mathrm{K}$, Adams JE, Armbrecht $\mathrm{G}$, Augat $\mathrm{P}$, Bogado $\mathrm{CE}$, Bouxsein ML, et al (2008) Clinical use of quantitative computed tomography and peripheral quantitative computed tomography in the management of osteoporosis in adults: the 2007 ISCD official positions. J Clin Densitom 11(1):123-162

3. Haase A, Arlinghaus $H$, Tentschert J, Jungnickel H, Graf $P$, Mantion A, et al. (2011) Application of laser postionization secondary neutral mass spectrometry/time-of-flight secondary ion mass spectrometry in nanotoxicology: visualization of nanosilver in human macrophages and cellular responses. ACS Nano 5(4):3059-3068

4. Hasegawa T, Matsuura H, Inagaki K, Haraguchi H (2003) Major-to-ultratrace elements in bone-marrow fluid as determined by ICP-AES and ICP-MS Anal Sci 19(1):147-150

5. Noor Z, Sumitro SB, Hidayat M, Rahim AH, Sabarudin A, Umemura T (2012) Atomic mineral characteristics of Indonesian osteoporosis by highresolution inductively coupled plasma mass spectrometry. Sci World J 372972

6. Hare D, Austin C, Doble P (2012) Quantification strategies for elemental imaging of biological samples using laser ablation-inductively coupled plasma-mass spectrometry. Analyst 137(7):1527-1537

7. Zoehrer R, Perilli E, Kuliwaba JS, Shapter JG, Fazzalari NL, Voelcker NH (2012) Human bone material characterization: integrated imaging surface investigation of male fragility fractures. Osteoporos Int 23(4):1297-1309

8. Roschger P, Paschalis EP, Fratzl P, Klaushofer K (2008) Bone mineralization density distribution in health and disease. Bone 42(3):456-466

9. Palmquist A, Emanuelsson L, Sjovall P (2012) Chemical and structural analysis of the bone-implant interface by TOF-SIMS, SEM, FIB and TEM: experimental study in animal. Appl Surf Sci 258(17):6485-6494

10. Fletcher JS, Vickerman JC, Winograd N (2011) Label free biochemical 2D and $3 \mathrm{D}$ imaging using secondary ion mass spectrometry. Curr Opin Chem Biol 15(5):733-740

11. Henss A, Rohnke M, El Khassawna T, Govindarajan P, Schlewitz G, Heiss C, et al. (2013) Applicability of ToF-SIMS for monitoring compositional changes in bone in a long-term animal model. J R Soc Interface 10(86):20130332

12. Kokesch-Himmelreich J, Schumacher M, Rohnke M, Gelinsky M, Janek J (2013) ToF-SIMS analysis of osteoblast-like cells and their mineralized extracellular matrix on strontium enriched bone cements. Biointerphases 8

13. Rohnke M, Henss A, Kokesch-Himmelreich J, Schumacher M, Ray S, Alt V, et al. (2013) Mass spectrometric monitoring of Sr-enriched bone cementsfrom in vitro to in vivo. Anal Bioanal Chem 405(27):8769-8780 
14. Vickerman JC, Briggs D (2013) ToF-SIMS: Materials Analysis by Mass Spectrometry, 2nd edition. IM Publications LLP and Surface Spectra Limited, Chichester, UK

15. Belu AM, Graham DJ, Castner DG (2003) Time-of-flight secondary ion mass spectrometry: techniques and applications for the characterization of biomaterial surfaces. Biomaterials 24(21):3635-3653

16. Burth R, Gelinsky M, Pompe W (1999) Collagen-hydroxyapatite tapes-a new implant material. Tech Textile 8:20-21

17. Bernhardt A, Lode A, Boxberger S, Pompe W, Gelinsky M (2008) Mineralised collagen-an artificial, extracellular bone matrix-improves osteogenic differentiation of bone marrow stromal cells. J Mater Sci Mater Med 19(1):269-275

18. Heiss C, Govindarajan P, Schlewitz G, Hemdan N, Schliefke N, Alt V, et al. (2012) Induction of osteoporosis with its influence on osteoporotic determinants and their interrelationships in rats by DEXA. Med Sci Monit 18(6)

19. Bradt JH, Mertig M, Teresiak A, Pompe W (1999) Biomimetic mineralization of collagen by combined fibril assembly and calcium phosphate formation. Chem Mater 11(10):2694-2701

20. Gelinsky M, Welzel PB, Simon P, Bernhardt A, Konig U (2008) Porous threedimensional scaffolds made of mineralised collagen: preparation and properties of a biomimetic nanocomposite material for tissue engineering of bone. Chem Eng J 137(1):84-96

21. McLeod K, Kumar S, Dutta NK, Smart RSC, Voelcker NH, Anderson Gl (2010) X-ray photoelectron spectroscopy study of the growth kinetics of biomimetically grown hydroxyapatite thin-film coatings. Appl Surf Sci 256(23):7178-7185

22. Lu HB, Campbell CT, Graham DJ, Ratner BD (2000) Surface characterization of hydroxyapatite and realted calcium phosphates by XPS and TOF-SIMS. Anal Chem 72:2886-2894

23. Chusuei CC, Goodman DW, Van Stipdonk MJ, Justes DR, Schweikert EA (1999) Calcium phosphate phase identification using XPS and time-of-flight cluster SIMS. Anal Chem 71(1):149-153

24. Malmberg P, Nygren $\mathrm{H}$ (2008) Methods for the analysis of the composition of bone tissue, with a focus on imaging mass spectrometry (TOF-SIMS). Proteomics 8(18):3755-3762

25. Vanselow K, Heuck F (2005) Radiologische Analyse des Knochen. Springer Medizin Verlag, Heidelberg, Germany

26. El Khassawna T, Boecker W, Govindarajan P, Schliefke N, Huerter B, Kampschulte M, et al. (2013) Effects of multi-deficiencies-diet on bone parameters of peripheral bone in ovariectomized mature rat. PLoS One 8(8)

27. Campi G, Ricci A, Guagliardi A, Giannini C, Lagomarsino S, Cancedda R, et al. (2012) Early stage mineralization in tissue engineering mapped by high resolution X-ray microdiffraction. Acta Biomater 8(9):3411-3418

28. Rey C, Combes C, Drouet C, Glimcher MJ (2009) Bone mineral: update on chemical composition and structure. Osteoporos Int 20(6):1013-1021

doi:10.1186/1559-4106-8-31

Cite this article as: Henss et al:: Quantification of calcium content in bone by using ToF-SIMS-a first approach. Biointerphases 2013 8:31.

\section{Submit your manuscript to a SpringerOpen ${ }^{\circ}$ journal and benefit from:}

- Convenient online submission

- Rigorous peer review

- Immediate publication on acceptance

- Open access: articles freely available online

- High visibility within the field

- Retaining the copyright to your article

Submit your next manuscript at $\gg$ springeropen.com 